Check for updates

Cite this: RSC Adv., 2019, 9, 5384

Received 29th December 2018

Accepted 4th February 2019

DOI: $10.1039 / \mathrm{c} 8 \mathrm{ra10625h}$

rsc.li/rsc-advances

\section{Organic matter and ammonia removal by a novel integrated process of constructed wetland and microbial fuel cells}

\begin{abstract}
Feng Liu, ${ }^{\text {ab }}$ Lei Sun, ${ }^{\mathrm{e}}$ Jinbao Wan, (D) *a Aiping Tang, ${ }^{\mathrm{c}} \mathrm{Mi}$ Deng ${ }^{\mathrm{a}}$ and Rongwei $\mathrm{Wu}^{\mathrm{d}}$
A novel approach, combining a microbial fuel cell (MFC) with an integrated vertical flow constructed wetland (IVCW), was developed, and its ability to simultaneously produce electrical energy while treating swine wastewater was verified. The system combined the singular water flow path of a traditional vertical flow constructed wetland (upflow and downflow)-microbial fuel cell (CW-MFC), which demonstrates better characteristics in the aerobic, anoxic, and anaerobic regions. It not only enhanced the antipollution load ability and the organic compound removal effect, but also improved the gradient difference in the redox potential of the system. The results showed that the structure and substrate distribution in the device could both improve swine wastewater treatment and increase bioelectricity generation capabilities. The average chemical oxygen demand (COD) and ammonia nitrogen $\left(\mathrm{NH}_{4}{ }^{+}-\mathrm{N}\right)$ removal efficiencies were as high as $79.65 \%$ and $77.5 \%$, respectively. Long-term and stable bioelectricity generation was achieved under continuous flow conditions. The peak values of the output voltage and power density were $713 \mathrm{mV}$ and $456 \mathrm{~mW} \mathrm{~m}^{-3}$. The activated carbon layer at the bottom of this system provided a larger surface for the growth of microbes. It showed significant promotion of the relative abundance of electrochemically active bacteria, which might result in the increase of bioelectricity generation in integrated vertical flow constructed wetland-microbial fuel cells (IVCW-MFCS). The electrochemically active bacteria, Geobacter and Desulfuromonas, were detected in the anodic biofilm by high-throughput sequencing analysis.
\end{abstract}

\section{Introduction}

Swine wastewater contains high concentrations of organic matter and other pollutants. Inadequate treatment or direct discharge of such wastewater into water bodies will result in serious water pollution and ecosystem damage. ${ }^{\mathbf{1}}$ With the rapid growth of large-scale pig breeding in China over the past few decades, the amount of pig farm pollutants has also increased. According to recent issues of the Survey Bulletin of China's Pollution Sources (2010), ${ }^{2}$ the organic pollution loading derived from livestock and poultry breeding in China accounts for $41.9 \%$ of the total organic pollution loading (represented by COD) of water. Among these pollution sources, the discharge of

\footnotetext{
${ }^{a}$ School of Resources Environmental \& Chemical Engineering, Nanchang University, Nanchang 330031, China. E-mail:492314365@qq.com; Tel: +8613576295727

${ }^{b}$ School of Chemistry and Chemical Engineering, Jiangxi Science and Technology Normal University, Fenglin Street, Nanchang, Jiangxi 330013, China

'School of Environment and Chemical Engineering, Nanchang Hangkong University, Nanchang 330063, China

${ }^{d}$ College of New Energy and Environmental Engineering, Nanchang Institute of Technology, Nanchang 330044, China

${ }^{e}$ School of Materials and Mechanical \& Electrical Engineering, Jiangxi Science and Technology Normal University, Fenglin Street, Nanchang, Jiangxi 330013, China
}

swine wastewater is the main contributor, which in some areas accounts for more COD than industrial and domestic sewage. ${ }^{2}$

Due to the environmentally benign characteristics, many bio-measures have been proposed to purify this kind of swine wastewater. The main techniques are: (i) anaerobic biological treatment technologies (e.g., biogas tanks, upflow anaerobic sludge blankets (UASB), anaerobic migrating blanket reactors $(\mathrm{AMBR})){ }^{3}$ (ii) aerobic biological treatment technologies (e.g., aerobic sequencing batch reactors and activated sludge), ${ }^{4}$ (iii) natural methods (e.g., constructed wetlands and stabilization ponds). ${ }^{5}$

Recently, most livestock and poultry breeding farm pollution treatment systems only contained anaerobic treatment installations, such as biogas tanks. Biogas is a key energy resource in the emerging global renewable energy resource market, and biogas technology is considered crucial for the transition away from fossil fuel dependence. ${ }^{6}$ The organic concentration in the effluent of biogas tanks is still high. A few farms also built aerobic facilities to deal with biogas slurry, but were unable to consistently operate these facilities due to high energy consumption and operating costs.

Constructed wetlands (CW) are an engineering technology that purify wastewater. The integrated vertical flow $\mathrm{CW}$ is a modification of the structure of the conventional constructed 
wetland. Compared with other biological treatment technologies, the integrated vertical flow constructed wetland possesses the advantages of lower investment and operating costs, better anaerobic and aerobic regions, better HRTs and anti-pollution load ability, and particularly better removal effects of the high nitrogen and phosphorus nutrients of livestock and poultry wastewater. These factors contribute to IVCW application in the treatment of swine wastewater. In the process of wastewater treatment, it has the potential of further energy conversion and recycling, and advanced treatment of organic pollutants. This system combined the singular water flow path of the traditional vertical flow CW-MFC (upflow and downflow), improved gradient difference in the redox potential of the system and reduction of the energy consumption in pumping influent into the upflow vertical subflow CW.

Microbial fuel cells (MFCs) are newly emerging methods of purifying pollutants and producing energy simultaneously. With advantages like low-sludge production, no-tail gas treatment, and low operating cost, studies on MFC opportunities have received extensive attention in recent years. ${ }^{7,8}$ In the anode, electrons and protons are generated by microbial oxidation and decomposition of organic compounds; the electrons are then transmitted to the cathode via an external circuit, and the produced protons are diffused into the cathode through the proton exchange membrane. ${ }^{9}$ The electron acceptor $\left(\right.$ as $\mathrm{O}_{2}$ ) in the cathode chamber is reduced after it receives the electrons and protons from the anode chamber. ${ }^{10}$ With the degradation of organic substrates in the anode and the reduction reaction in the cathode. ${ }^{11}$

The constructed wetland (CW) has structural advantages for creating an MFC. ${ }^{12}$ The CW system contains better anaerobic regions, aerobic regions, and redox gradients, and its higher specific surface area in the stroma is favorable for the adsorption of an electron mediator, making it possible to couple MFCs with CWs. The coupling of an MFC with the widely used CW technology has great practical significance and application prospects. ${ }^{13}$ However, in retrospect, previous works on CW-MFC revealed several limitations on the existing structures (concentrated in vertical and horizontal flow constructed wetlands). Excessive or unstable influent pollution will influence the treatment effect and power generation performance of the system. ${ }^{14,15}$ At the same time, a certain amount of energy is consumed in the application of up-flow influent.

In this study, we designed and constructed an IVCW-MFC integrated system that enhanced the wastewater treatment effect and realized the synchronous production of electricity. Actual swine wastewater was used in this system. The influent model of this IVCW-MFC differed from the conventional upflow vertical subflow constructed wetland. This system combined the singular water flow path of the traditional vertical flow CW-MFC (upflow and downflow), improved the gradient difference in the redox potential of the system and reduced the energy required to pump influent into the upflow vertical subflow $\mathrm{CW}$. On one hand, the anode was placed deep in the system to eliminate the influence of atmospheric air, and the cathode was exposed to atmospheric air. This ensured maximum reduction of dissolved oxygen (DO) in the anode region and provided an anaerobic environment for the anode. On the other hand, the energy free influent mode coupled plant roots in front of the anode area, which contained the aerobic nitrification phase and enhanced the nutrient removal effects and anti-pollution load capacity. Furthermore, high or fluctuating pollution loads in the influent did not affect the treatment efficiency and the bioelectricity generation performance. It demonstrated good practicability and economy, and rendered the system more suitable for practical engineering operation in the future. In this study, the wastewater treatment performance was assessed via markers such as COD, $\mathrm{NO}_{3}{ }^{-}-\mathrm{N}$, and $\mathrm{NH}_{4}{ }^{+}-\mathrm{N}$ in open- and closed-circuit systems. Additionally, its bioelectricity generation properties were assessed via the closed-circuit system's voltage output, power density, current density, and Coulomb efficiency (CE). Furthermore, the microbial community structure of electrogenic bacteria was tested by a high-throughput sequencing analysis. The feasibility, effectiveness and potential synergy of the integrated system for wastewater treatment and synchronous power generation was tested.

\section{Methods}

\subsection{Reactor set-up and configuration}

In this study, the IVCW-MFC reactor was made of a $50 \mathrm{~cm}$ tall polyacrylic plastic box with a square cross-section of $40 \times$ $20 \mathrm{~cm}$, as shown in Fig. 1. The reactor was placed in the laboratory, and the average temperature during the entire period of operation, which occurred in summer, was $33 \pm 5{ }^{\circ} \mathrm{C}$. In order to improve the system's effect on the anaerobic and aerobic environment and improve the redox gradient, the reactor was divided into downflow and upflow regions by a polyacrylic plastic; at the bottom of $5 \mathrm{~cm}$ was left unblocked. The influent first arrived in the downflow area, passed the anode region, moved through the bottom to the upflow area, and finally arrived at the cathode region.

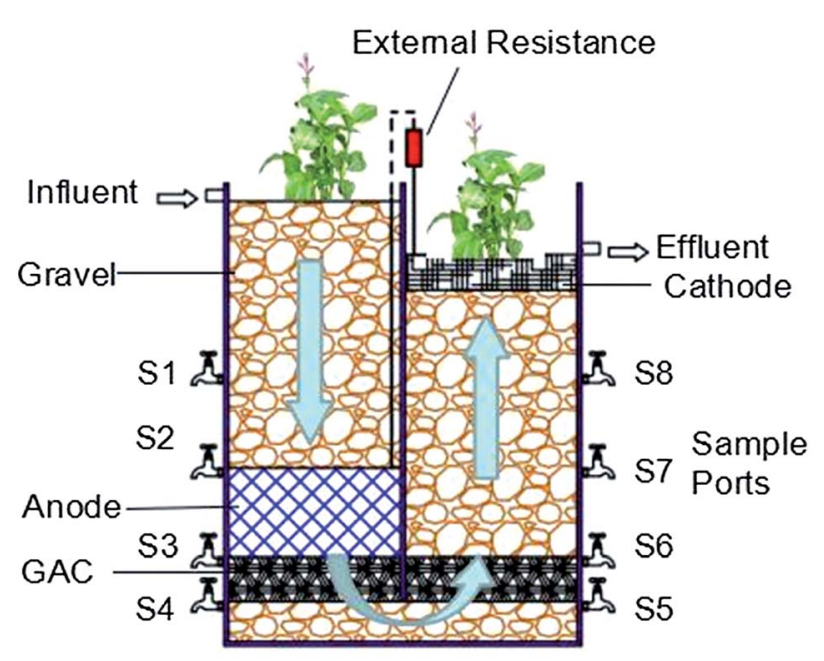

Fig. 1 The structure of the IVCW-MFC. 
The sampling ports were built at heights $5,10,20$, and $30 \mathrm{~cm}$ from the bottom of the reactor. In order to improve the electrical conductivity of the device, the anode adopted a stainless-steel wire mesh to wrap the activated carbon particles in $(20 \mathrm{~cm} \times$ $20 \mathrm{~cm} \times 10 \mathrm{~cm})$ that was buried in the downlink area $(30-40 \mathrm{~cm})$, complying with the anodic condition of the MFC, which was in anaerobic condition. ${ }^{16}$ The high specific surface area made it a good medium for the attachment of microorganisms, and it exhibited characteristics of activated carbon like good biocompatibility and moderate electrical conductivity. ${ }^{17}$ Carbon felt was used as the cathode $(20 \mathrm{~cm} \times 20 \mathrm{~cm})$ and arranged on the upflow surface, and it could be combined with plant roots to promote oxygen transport and diffusion to create better aerobic conditions. An activated carbon layer was set at a height $5 \mathrm{~cm}$ above the bottom in both the downflow and upflow regions. This layer supplied sufficient supporters for anaerobic heterotrophic bacteria, which continuously degraded organic compounds left after the anode removal. This process reduced the amount of organic compounds reaching the cathode. Gravels were used to fill in other parts of the reactor. The volume of the whole container was $37.8 \mathrm{~L}$, with an effective volume of $11.5 \mathrm{~L}$. Each column was planted with Canna indica and wrapped in black plastic to prevent algae growth. ${ }^{18}$

One IVCW-MFC, termed IVCW-MFC-C, was operated in closed-circuit mode with bioelectricity generation, while the other, IVCW-MFC-O, was operated in open-circuit mode without bioelectricity generation (i.e., the external circuit was disconnected, which was a set-up similar to a single wastewater treatment composite vertical flow $\mathrm{CW}$ ). There were three parallel groups in each system. In the IVCW-MFC-C system, stainless-steel screen mesh, carbon felt, and metal titanium wires were used to connect the anode and cathode with an external resistance of $1000 \Omega$ to complete the circuit. The voltage output was recorded during the study with a data logger (ADS1115 and CH341A LOGGER China).

\subsection{Inoculation and swine wastewater}

Prior to the experimental start-up, the anodes of the IVCW-MFC were inoculated with anaerobic digestion sludge sourced from Pengyao Wastewater Treatment Plant, Nanchang, China, for a period of two weeks. In the laboratory, during the two-weeks anaerobic culture period at room temperature $\left(\sim 28{ }^{\circ} \mathrm{C}\right)$, artificial wastewater was added directly to the anaerobic digestion sludge. Glucose and ammonium chloride were used as the carbon source (COD concentration: $700 \mathrm{mg} \mathrm{L}^{-1}$ ) and nitrogen source $\left(\mathrm{NH}_{4}{ }^{+}-\mathrm{N}\right.$ concentration: $\left.200 \mathrm{mg} \mathrm{L}^{-1}\right)$, respectively. Then, the miscible liquids were pumped continuously into the reactor (each reactor received $4.0 \mathrm{~L}$ of miscible liquids) from the water intake. The systems were operated for about a mouth until the reproducible maximum voltages were observed.

The swine wastewater used in this study was wastewater discharged after anaerobic treatment in a biogas tank and upflow anaerobic sludge blanket at Zhenghua Farm (Nanchang, China, $28^{\circ} 51^{\prime} 45^{\prime \prime} \mathrm{N}, 116^{\circ} 9^{\prime} 57^{\prime \prime} \mathrm{E}$ ), which breeds live pigs with 20000 livestock on hand. The COD concentrations varied from 324$708 \mathrm{mg} \mathrm{\textrm {L } ^ { - 1 }}$, while the ammonium $\left(\mathrm{NH}_{4}{ }^{+}-\mathrm{N}\right)$ concentrations varied from 138-284 $\mathrm{mg} \mathrm{L}^{-1}$. Under continuous, saturated flow conditions, each CW-MFC treated $5.75 \mathrm{~L}$ of swine wastewater daily with an HRT of two days. The MFCs and IVCW-MFCs operate more efficiently under a lower organic matter load and can be better applied in the secondary treatment of wastewater.

\subsection{Analysis}

From the influent along the water flow to the effluent (influent, S1, S2, S3, S4, S5, S6, S7, S8, and effluent), the samples were collected and analyzed. In order to reduce the effect of diurnal variation on the removal efficiency, samples were collected once every two days at 10:00 local time while the system operation, ambient temperature, and weather were noted. The wastewater treatment performance of the IVCW-MFC was determined by taking daily measurements of $\mathrm{COD}$, nitrate $\left(\mathrm{NO}_{3}{ }^{-}-\mathrm{N}\right)$, and $\mathrm{NH}_{4}{ }^{+}-\mathrm{N}$ from each sampling port. The soluble CODs were measured using the potassium dichromate method. $\mathrm{NO}_{3}{ }^{-} \mathrm{N}$ and $\mathrm{NH}_{4}{ }^{+}-\mathrm{N}$ were determined using the phenol-2-sulfonic acid method and the sodium reagent method, respectively, according to standard methods.

The polarization curve method was used to measure the maximum power density. At first, the steady state voltage of the open circuit was noted. Then the steady state voltage of the closed circuit with external resistance varying from $10000 \Omega$ to $5 \Omega$ was noted. The value at the highest point of this curve is the maximum power density. The slope of the $U-I$ circuit $(U=I R)$ was the internal resistance performance.

The microbial communities of the IVCW-MFC in the openand closed-circuit modes were examined using highthroughput 16S rRNA pyrosequencing technology. Because of the different influences of the applied current on the anode and cathode regions, the substrate-attached biofilms from these two regions were sampled for microbial community analysis.

Samples for microbial community analysis were collected at the end of the experiments by scraping the anode and cathode surface and centrifuging the samples at $10000 \mathrm{rpm}$ for $3 \mathrm{~min}$. The cathode carbon felt was thoroughly washed with distilled water and then cut into small pieces. Genomic DNA of the biofilms was extracted from the cathode pieces using an extraction kit (E.Z.N.ATM Mag-Bind Soil DNA Kit, Omega, USA) following the manufacturer's instructions. The Illumina MiSeq platform (Shanghai Sangon Biotech Co., Ltd) targeted the V3-V4 region of the 16S rRNA gene. Libraries were constructed through polymerase chain reactions using primers with the Illumina overhang adapter sequences, 341F (CCCTACACGACGCTCTTCCGATCTG (barcode) CCTACGGGNGGCWGCAG) and 805R (GACTGGAGTTCCTTGGCACCCGAGAATTCCA GACTACHVGGGTATCTAATCC), as specified by the manufacturer's instructions. We used the software R's "vegan" package (version 2.0-10) to calculate the beta diversity distance matrix according to the operational taxonomic unit abundance of each sample, with the method of calculating the distance between samples being BrayCurtis. A sample-clustering tree graph can directly reflect the similar and different relationships among multiple samples through the tree structure. Firstly, a hierarchical clustering analysis is carried out according to the beta diversity distance 
matrix. Then, the tree structure is constructed by using the unweighted pair group method with the arithmetic mean algorithm, and the tree relation form is obtained for visual analysis. The software $\mathrm{R}$ version 3.2 was used to display the statistical results of the species taxonomy. In the heatmap, each color reflects the abundance value of a community distribution, ranging from blue to red to represent abundances of 0 to 28.48. At the same time, the sample and community distribution information are clustered and rearranged, and the results after clustering are displayed in heatmap by using R's gplots package. Therefore, it can reflect the similarities and differences between community distributions for different classification levels.

\subsection{Calculation}

The COD and $\mathrm{NH}_{4}{ }^{+}-\mathrm{N}$ removal efficiency can be calculated by using the formula below:

$$
\mathrm{CE}=\left[\left(C_{\text {inf }}-C_{\text {eff }}\right) / C_{\text {inf }}\right] \times 100 \%,
$$

where $C_{\text {inf }}$ is the COD (or $\mathrm{NH}_{4}{ }^{+}-\mathrm{N}$ ) concentration of the influent, and $C_{\text {eff }}$ is the COD (or $\mathrm{NH}_{4}{ }^{+}-\mathrm{N}$ ) concentration of the effluent $\left(\mathrm{mg} \mathrm{L}^{-1}\right)$.

The calculation formulae related to bio-production are as follows:

$$
\begin{gathered}
I=U / R(\text { Ohm's law }), \\
P=I \times U, \\
\mathrm{Pd}=P / V, \\
\mathrm{CE}=(M \times I) /(F \times q \times n \times \Delta \mathrm{COD}),
\end{gathered}
$$

where $U(\mathrm{~V})$ is the measured cell voltage; $R(\Omega)$ is the external resistance; $I$ (A) is the current of the circuit; $P(\mathrm{~W})$ is the power; $V$ $\left(\mathrm{m}^{3}\right)$ is the effective volume of the anode; $\mathrm{Pd}\left(\mathrm{W} \mathrm{m} \mathrm{m}^{-3}\right)$ is the power density; CE (\%) is the coulombic efficiency; and $Q(\mathrm{C})$ is charge quantity. In addition, $M$ is the molecular mass of $\mathrm{O}_{2}(32 \mathrm{~g}$ $\left.\mathrm{mol}^{-1}\right) ; I$ is current (A); $F$ is Faraday's constant $\left(\mathrm{C} \mathrm{mol}^{-1}\right)$, which is $96485 ; q$ is flow rate $\left(\mathrm{L} \mathrm{s}^{-1}\right) ; n$ is the number of electrons donated per mole of $\mathrm{O}_{2}\left(\mathrm{~mole}-/ \mathrm{mol} \mathrm{O}_{2}\right)$, which is 4 ; and $\Delta \mathrm{COD}$ represents the change in COD between the influent and effluent $\left(\mathrm{g} \mathrm{L}^{-1}\right)$.

The charge quantity $(Q)$ of the external circuit was calculated using the following formula:

$$
Q=\int_{0}^{T} I \mathrm{~d} t
$$

where $I(\mathrm{~A})$ is the current through the load; $T(\mathrm{~s})$ is the time of power output; and one coulomb is equivalent to the charge of approximately $6.24146 \times 10^{18}$ electrons. The internal resistance was calculated from the linear region of the polarization curve. ${ }^{19}$

\section{Results and discussion}

\subsection{COD removal}

The swine wastewater was provided for 92 consecutive days. Fig. 2(a) depicts the stable COD removal by the IVCW-MFC system under long-term operation; the influent COD concentrations varied from $324-708 \mathrm{mg} \mathrm{L}^{-1}$, and the average concentration of COD entering the IVCW-MFC was $505 \mathrm{mg} \mathrm{L}^{-1}$. After stable treatment with a two-day HRT, the average effluent concentration of the closed- and open-circuit systems were $102.7 \mathrm{mg} \mathrm{L}^{-1}$ and $181.1 \mathrm{mg} \mathrm{L}^{-1}$, respectively, and the average removal effect of COD was $79.65 \%$ and $64.71 \%$ in each system, respectively. Results showed that the COD removal of the closed-circuit system was $14.94 \%$ higher than for the opencircuit system, and the synchronous electric generation from the closed-circuit system could improve wastewater treatment. It may have resulted from the use of the anode of the CW-MFC as a temporary electron acceptor to contribute to the process of anaerobic treatment. ${ }^{20}$

In Fig. 2(b), the regression analysis between COD removal $(\mathrm{g}$ $\left.\mathrm{m}^{-2} \mathrm{~d}^{-1}\right)$ and COD loading $\left(\mathrm{g} \mathrm{m}^{-2} \mathrm{~d}^{-1}\right)$ can be seen. $R^{2}$ values of IVCW-MFC-C and IVCW-MFC-O were 0.9749 and 0.9030 respectively, which indicated that $\mathrm{COD}$ removal effect prediction in IVCW-MFC-C mode was more reliable in IVCW-MFC-C mode in the system over the 92 day study. The pollution load varied during the operation with swine wastewater, but the stable COD removal efficiency and the anti-load ability of the IVCW-MFC were confirmed. This may be a result of the overall aerobic-anaerobic-aerobic process in the IVCW-MFC. Especially, in the aerobic phase, the Canna indica roots formed a special microbial community and produced oxygen in rhizodegradation, both of which promote the degradation of nitrogen and organic matter.

It is clear from Fig. 2(c) that, compared with an open-circuit system, the COD concentration in the closed-circuit system reduced more intensely from the inlet to $\mathrm{S} 1-\mathrm{S} 3$, followed by a gradual reduction from $\mathrm{S} 4$ to $\mathrm{S} 9$. The anodic region became the main area of COD removal, with a total of $58.93 \%$ COD reduction occurring. The microcurrent surroundings and exudates from plant roots could promote the growth and activity of microorganisms and wetland plants, ${ }^{21}$ and some complex organic compounds can be hydrolyzed from even a small amount of oxygen released from roots. The hydrolytic products, such as acetic acid, propionic acid, butyric acid, and other low-molecular organic compounds, were used by electrogenic bacteria to promote the removal of pollutants in the swine wastewater, ${ }^{22,23}$ and the unused organic matter would be removed further. The COD removal rate reached $73.3 \%$ in IVCW-MFC-C at S5 and S6 after the activated carbon layer treatment and was $22.9 \%$ higher than in IVCW-MFC-O.

The concentration of organic matter was reduced greatly when reaching the cathode region. If the concentration of organic matter in the cathode was high, the oxygen would be consumed during the decomposition process, and the aerobic surroundings would be damaged in the cathode, affecting the reduction reaction necessary to form the complete circuit. This would cause mass propagation of heterotrophic bacteria, limit the mutual transmission between the reactant and the product on the electrode, and bring harmful effects to the bioelectricity generation ability.

It is worth noting that COD decreased sharply in the anode (electricity producing) layer of IVCW-MFC-C from S2 to S3, and 

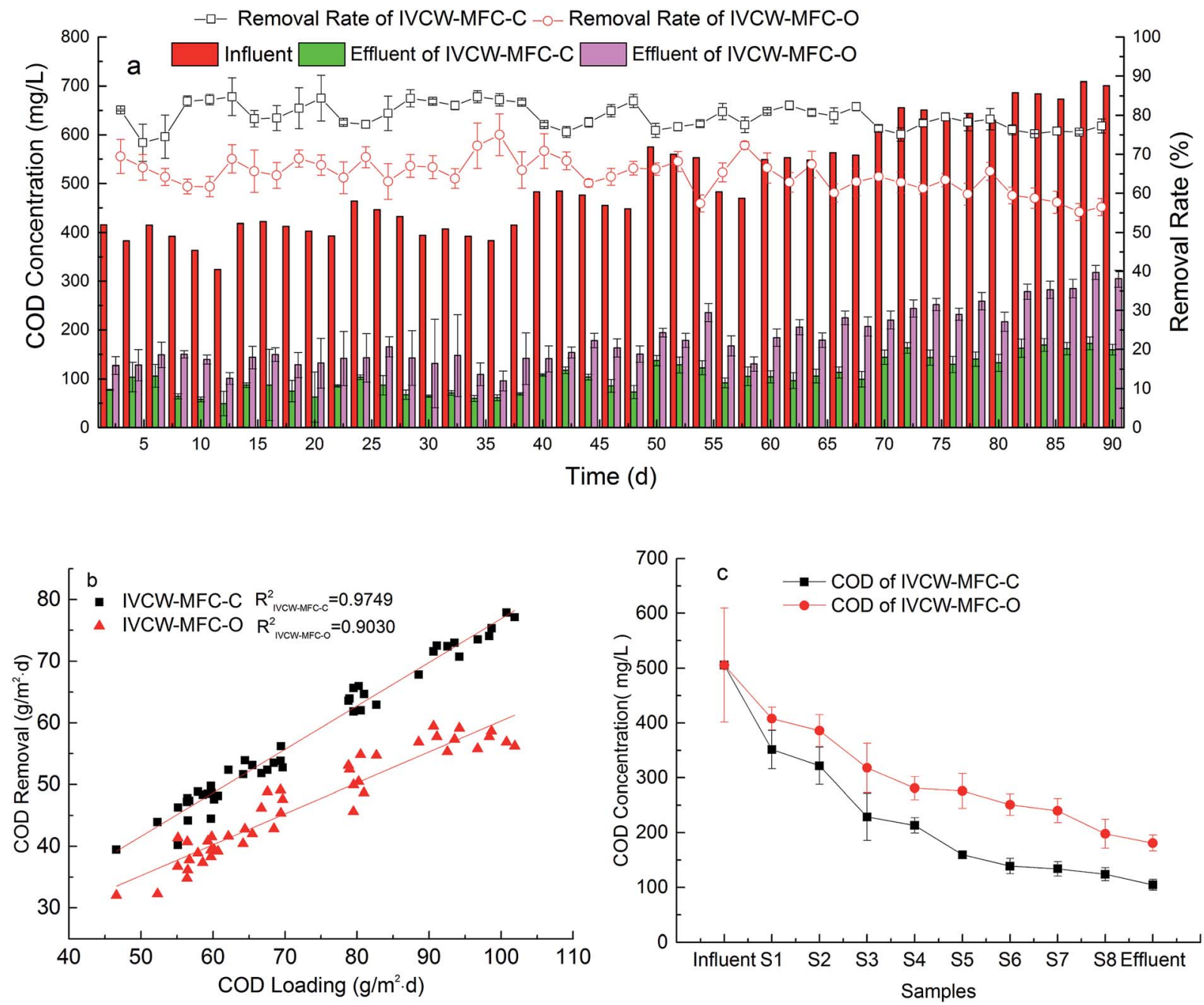

Fig. 2 (a) COD removal efficiency, (b) correlation between COD loading and its removal, and (c) variations in COD concentration with water flow.

the removal amount was trending higher than the total amount in the pure activated carbon layer: S3-S6. The COD removal ratio reached $18.3 \%$, which is $26.9 \%$ higher than for the same region of IVCW-MFC-O. While the anode layer occupied only $10.4 \%$ of the entire liquid volume, its role in removing organic pollutants was emphasized. Fang ${ }^{13}$ developed similar results, in which the COD removal ratio was enhanced $12.7 \%$ by the anode action of the system. The anode provided a suitable growth environment to the biomembrane and was also an insoluble final electron receptor that increased the metabolic rate of anaerobic bacteria, ${ }^{\mathbf{1 3}}$ which contributed to the reduction of COD. The connection of external circuits also promoted the growth of electrogenic bacteria in the anode region and enhanced nutrient removal. ${ }^{24}$

\subsection{Nitrogen removal}

Swine wastewater is characterized by high nitrogen concentrations, which is a key index of treatment. The reactor was reformed in the traditional $\mathrm{CW}$ structure to enhance the denitrification effect, and it was separated into aerobic, anoxic, and anaerobic regions without power. The distributions of $\mathrm{NH}_{4}{ }^{+}-\mathrm{N}$ and $\mathrm{NO}_{3}{ }^{-}-\mathrm{N}$ were then analyzed in this system.

As shown in Fig. 3(a), the influent $\mathrm{NH}_{4}{ }^{+}-\mathrm{N}$ concentrations varied from 138-284 $\mathrm{mg} \mathrm{L}^{-1}$, with an average concentration of $215 \mathrm{mg} \mathrm{L}^{-1}$. The pollution load varied greatly; however, the overall ammonia removal efficiency remained stable. The average removal rate of IVCW-MFC-C reached $77.5 \%$, which was higher than that of IVCW-MFC-O by $57.6 \%$, an improvement over the Knight ${ }^{25}$ study of 135 wastewater treatment plants, whose CW denitrification effect was $48 \%$. In addition, the ammonia nitrogen removal per unit area was $12 \mathrm{~g} \mathrm{~m}^{-2} \mathrm{~d}^{-1}$, which was higher than that obtained in previous studies $(8.5 \mathrm{~g}$ $\left.\mathrm{m}^{-2} \mathrm{~d}^{-1}\right) .{ }^{1}$ These results indicate that the integration of MFCs in the CW system promoted the decomposition of the swine wastewater.

As shown in Fig. 3(b), the $\mathrm{NH}_{4}{ }^{+}-\mathrm{N}$ concentration decreased drastically from the influent to $\mathrm{S} 2$, and the decrease in $\mathrm{NH}_{4}{ }^{+}-\mathrm{N}$ removal was met with an increase in $\mathrm{NO}_{3}{ }^{-}-\mathrm{N}$ concentration. The increased $\mathrm{NO}_{3}{ }^{-}-\mathrm{N}$ accounted for $49.02 \%$ (IVCW-MFC-C) and $46.12 \%$ (IVCW-MFC-O) of the $\mathrm{NH}_{4}{ }^{+}-\mathrm{N}$ removal in the same sample layer, indicating that nitrification occurred in 

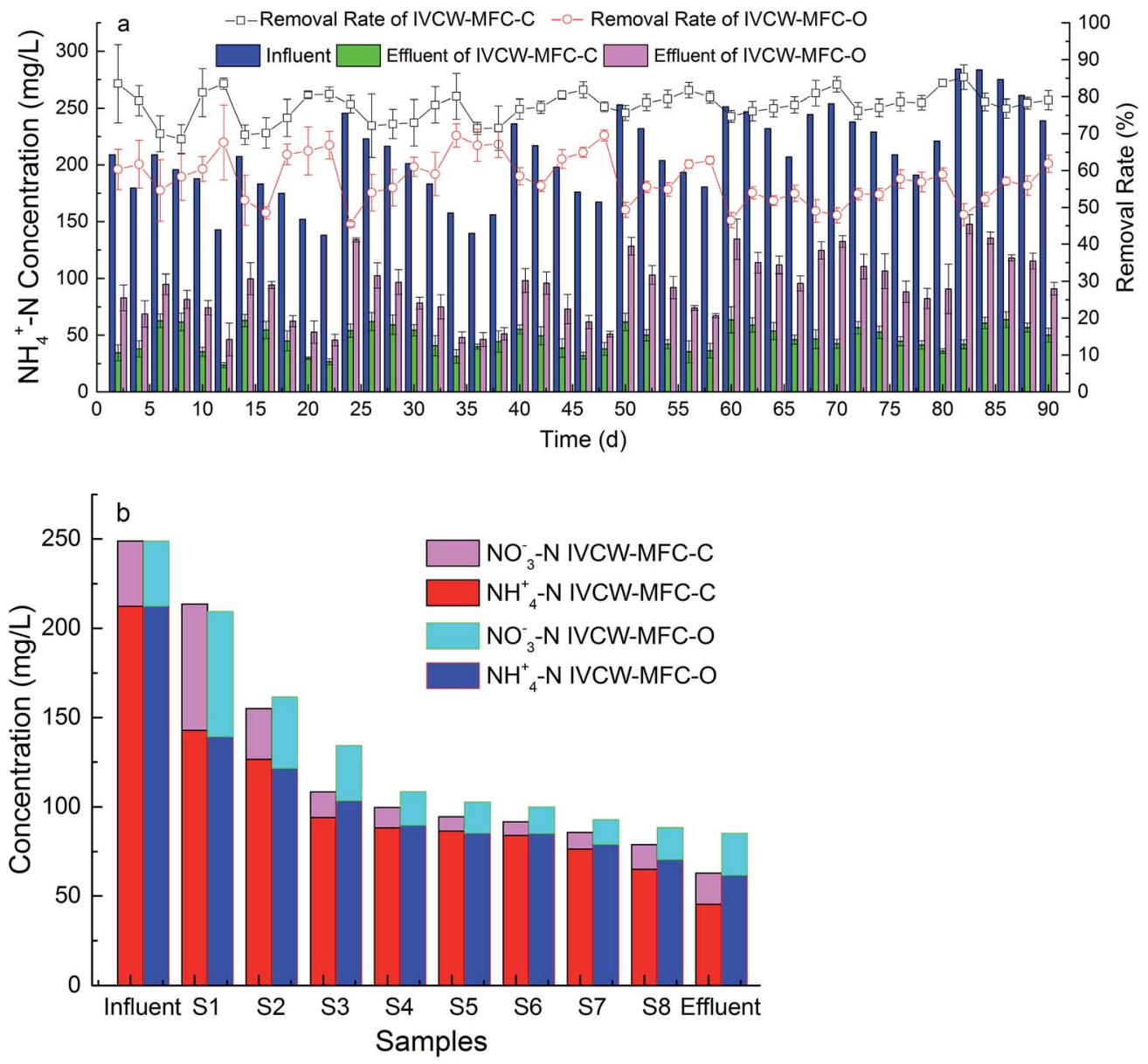

Fig. 3 (a) $\mathrm{NH}_{4}{ }^{+}-\mathrm{N}$ removal efficiency and (b) the concentration varieties of $\mathrm{NH}_{4}{ }^{+}-\mathrm{N}$ and $\mathrm{NO}_{3}{ }^{-}-\mathrm{N}$ along the water flow.

front of the anode area. In this IVCW-MFC system the improvement of nitrification can be attributed to the advantage of the downflow in the anode and the oxygen supply from the plant roots, increasing the ammonia nitrogen removal rate. The $\mathrm{NH}_{4}{ }^{+}-\mathrm{N}$ reduction in the anode region alone accounted for $71.4 \%$ of the total reduction of the IVCW-MFC-C system. The $\mathrm{NO}_{3}{ }^{-}-\mathrm{N}$ concentration reduction was primarily due to the organic substrates and the plant absorption and denitrification. ${ }^{26}$ The $\mathrm{NO}_{3}{ }^{-}-\mathrm{N}$ decreased from its highest concentration at $70.62 \mathrm{mg} \mathrm{L}^{-1}$ (IVCW-MFC-C) and $70.32 \mathrm{mg} \mathrm{L}^{-1}$ (IVCW-MFC-O) to its lowest concentration at $17.56 \mathrm{mg} \mathrm{\textrm {L } ^ { - 1 }}$ (IVCW-MFC-C) and $23.58 \mathrm{mg} \mathrm{L}^{-1}$ (IVCW-MFC-O), although a small amount of ammonia nitrogen nitrification occurred in the aerobic stage of the cathode, resulting in a slight increase in $\mathrm{NO}_{3}{ }^{-}-\mathrm{N}$; the overall nitrate reduction, however, decreased up to $75.13 \%$ (IVCWMFC-C) and $66.47 \%$ (IVCW-MFC-O). These results suggest that the IVCW-MFC-C mode promoted nitrogen removal, and the integrated system had a better removal effect on nitrate than does the traditional system. ${ }^{27}$

The high concentration of wastewater in the anode region promoted the growth of biofilm in the anode area, and the oxygen diffusion was limited by the accumulation of organic matter, which increased the anoxic region at the bottom of the system. The sufficient carbon sources improved the nitrate removal. ${ }^{28}$ Meanwhile Nguyen et al. ${ }^{29,30}$ investigated nitrate removal in MFC by using abiotic and biotic cathode. With the increase of imposed cell potential, enhanced nitrate removal efficiency from $18 \%$ to $43 \%$. On the other hand, the cathode region had a better reoxygenation effect under the double action of the plants and air cathodes. At the same time, sufficient organic matter and carbon sources could promote the growth of aerobic denitrifiers in the cathode region. These denitrifying bacteria could use both oxygen and nitrate as terminal electron acceptors to denitrify the system under aerobic conditions. ${ }^{\mathbf{1 4 , 1 9}}$

\subsection{Bioelectricity generation}

To study the power production effect of the system in the purification of swine wastewater, the voltage values were recorded every six minutes for 92 days continuously in the IVCW-MFC-C mode, as shown in Fig. 4(a). In the early stages of the experiment, the voltage reached a stable output after two increases. The swine wastewater was rich in dissolved organic matter, which was easily decomposed by microorganisms. Furthermore, the activated carbon layer in the anode region of this system provided a larger surface for the growth of microbes. Increasing the bacteria might result in the increase in electrons and protons and lead to a stable voltage output rapidly. The 

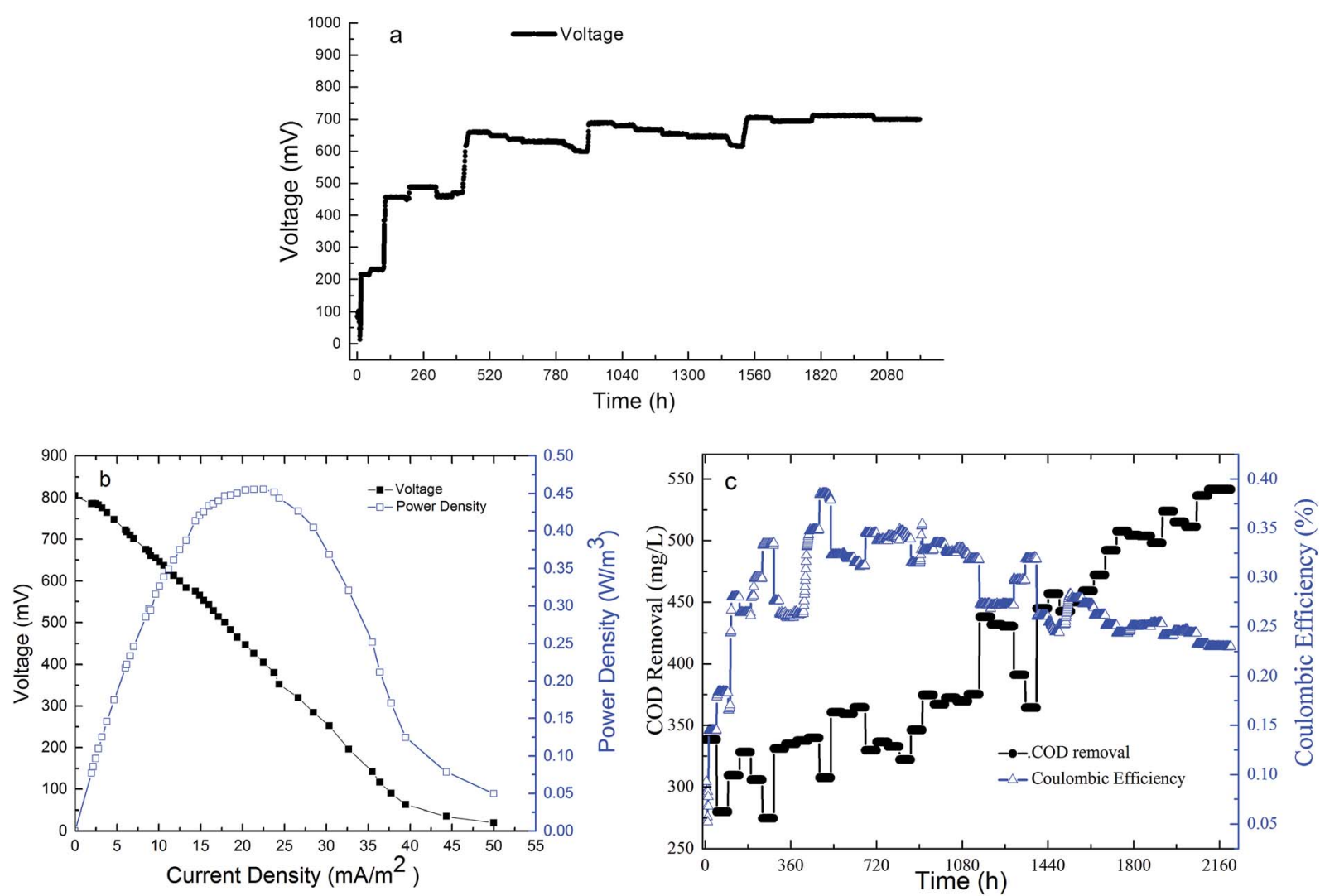

Fig. 4 (a) Electricity generation performance, (b) polarization and power density curves, and (c) the Coulomb efficiency variations with the COD removal amount.

output voltage required approximately six days to reach the first stable phase. Then, the exclusive bacterial flora gradually formed in approximately the next twelve days, and under the effect of a closed external circuit, the output voltage achieved the second stable power generation phase. The biofilm structure on the substrate and electrode surface (including microorganism species, abundance, and other factors) was gradually stable, and more electrons and protons were produced by microorganism decomposition and oxidation of organic matter in the swine wastewater, which promoted electricity production. In the stable operation period, the output voltage of the system was in the range of 598-713 $\mathrm{mV}$ which was higher than the values of studied by Pratiksha et al., ${ }^{24}$ Wang et al.,${ }^{27}$ and José et al. ${ }^{31}$ Based on the cathode half-cell reaction $\left(\mathrm{O}_{2}+4 \mathrm{H}^{+}+4 \mathrm{e}^{-}\right.$ $\rightarrow 2 \mathrm{H}_{2} \mathrm{O}$ ) and oxygen as the final electron receptor, the air cathodes and plants photosynthesis provided high oxygen concentrations for the cathode. ${ }^{32}$ The particular water flow path and the activated carbon layer at the bottom prevent the organic compounds from reaching the cathode. In this phase, the COD removal amount occupied $92.03 \%$ of the whole COD removal amount of the system. This effectively prevents the large amount of organic compound from consuming the oxygen in the cathode and promoted a cathodic redox reaction to reduce the cathode resistance and increase the cathode potential. At the same time, a continuous influx was used in this experiment; the wastewater flowed from anode to cathode while transporting protons, shortening the $\mathrm{pH}$ gradient between the two points and avoiding the small effect of electricity production caused by excess acidity at the anode or excess alkalinity at the cathode. ${ }^{33}$

The electrochemical performance of IVCW-MFC was evaluated by polarization and power density curves obtained at the end of experiment. As shown in Fig. 4(b), the maximum power density was $0.456 \mathrm{~W} \mathrm{~m}^{-3}$ (when the current density was $22.5 \mathrm{~mA}$ $\mathrm{m}^{-2}$ ), which was higher than the maximum power densities of $0.093 \mathrm{~W} \mathrm{~m}^{-3}$ from Oon et al. ${ }^{16}$ and $0.302 \mathrm{~W} \mathrm{~m}^{-3}$ from Zhou et al. ${ }^{32}$ The internal resistance was one of the limiting factors of the CW-MFC bioelectricity generation ability, which directly affected the voltage output of the system. ${ }^{34}$ The internal resistance of the system measured by the polarization curve method was $463.66 \Omega$, which is theoretically close to the external resistance value, $450 \Omega$. The lower internal resistance was due to the high conductivity of the electrode and the advantages of the system structure, such as continuous water flow. ${ }^{35}$ The internal resistance of CW-MFC was mainly composed of the activation internal resistance, ohmic resistance, and concentration resistance. The activation internal resistance in this study was mainly rooted in the activation energy needed for an electrochemical reaction on the surface of the carbon felt air cathode and the stainless-steel wire mesh coated granular active carbon anode. Research on MFCs has indicated that the catalytic converter in the electrochemical reaction could reduce the 
activation internal resistance when the microbes grow well. ${ }^{36}$ The swine wastewater treated in this study contained a great deal of dissolved organic matter that could satisfy microbial metabolism nutrient needs, prevent the substrate transport from being limited (which reduces the internal resistance by increasing the electrical conductivity of the substrate), and improve the bioelectricity generation ability of CW-MFC.

The output voltage varied with the COD concentration. The ohmic resistance in this study was mainly rooted in the conductivity of electrolytes, electrodes, and surface biofilms. The metal titanium wires, as perfect conductors, hardly corroded and were interwoven through the carbon felt and connected the outside circuit to increase the electrical conductivity of the cathode. The microbes attached to the electrode surface could also reduce the electrode resistance. ${ }^{37}$

During the operation period, a total of $7137 \mathrm{C}$ of electric charge were produced, with an average of $6.74 \mathrm{C} \mathrm{d}^{-1} \mathrm{~L}^{-1}$. The maximum coulombic efficiency (CE) was $0.386 \%$, which close to the values obtained by Doherty et al., ${ }^{18}$ Fang et al., ${ }^{13}$ and Zhou et $a l .{ }^{32}$ As indicated in eqn (5), CE was closely related to the COD removal of the reactor; this was also confirmed in Fig. 4(c), where the CE curve trend is opposite that of COD removal. The large number of microorganisms from the swine wastewater competed with the electrogenic bacteria in the reactor, which resulted in most organic compounds being used in the anaerobic digestion reaction e.g., consumed in methanogenic or fermentation processes; Kim et al. ${ }^{38}$ Only a small fraction of organic matter was used as a bioelectron donor. Charge transfer resistance due to the slow activation rate on the anode and cathode electrode constitute the dynamic transfer limit. This was also one of the main reasons for the low CE value in the IVCW-MFC and even in the general CW-MFC.

\subsection{The influence of electrodes on electrogenic bacteria}

The microorganisms on the electrodes presented unique structural characteristics while simultaneously purifying swine wastewater and producing electricity. Swine wastewater was known to contain various kinds of useful bacteria, including exoelectrogens, hydrogen-producing bacteria, and methanogens for anaerobic digestion, ${ }^{39}$ and the activated sludge from wastewater treatment that was inoculated as the seed sludge into all IVCW-MFCs was identical. To identify the microbial communities from the two operation modes, 223528 raw sequences and 217268 high-quality reads with an average length of $\sim 422$ bp were obtained. The Shannon diversity index $\left(H^{\prime}\right)$ indicated both richness (the number of species present) and evenness (how each species is distributed), showing that the anode surface biofilm biodiversity $\left(H^{\prime}=5.32\right.$, from IVCWMFC-C) was the highest among the four electrode samples while the biodiversity $\left(H^{\prime}=4.57\right)$ was lowest from the same sampling position with IVCW-MFC-O. The cathode surface biofilm biodiversity $\left(H^{\prime}=5.06\right.$ from IVCW-MFC-C; $H^{\prime}=5.08$ from IVCW-MFC-O) for both IVCW-MFCs was similar. The results revealed that the closed-circuit mode resulted in high biodiversity on the anode, which promoted the generation of bioelectricity and the degradation of organic compounds. The
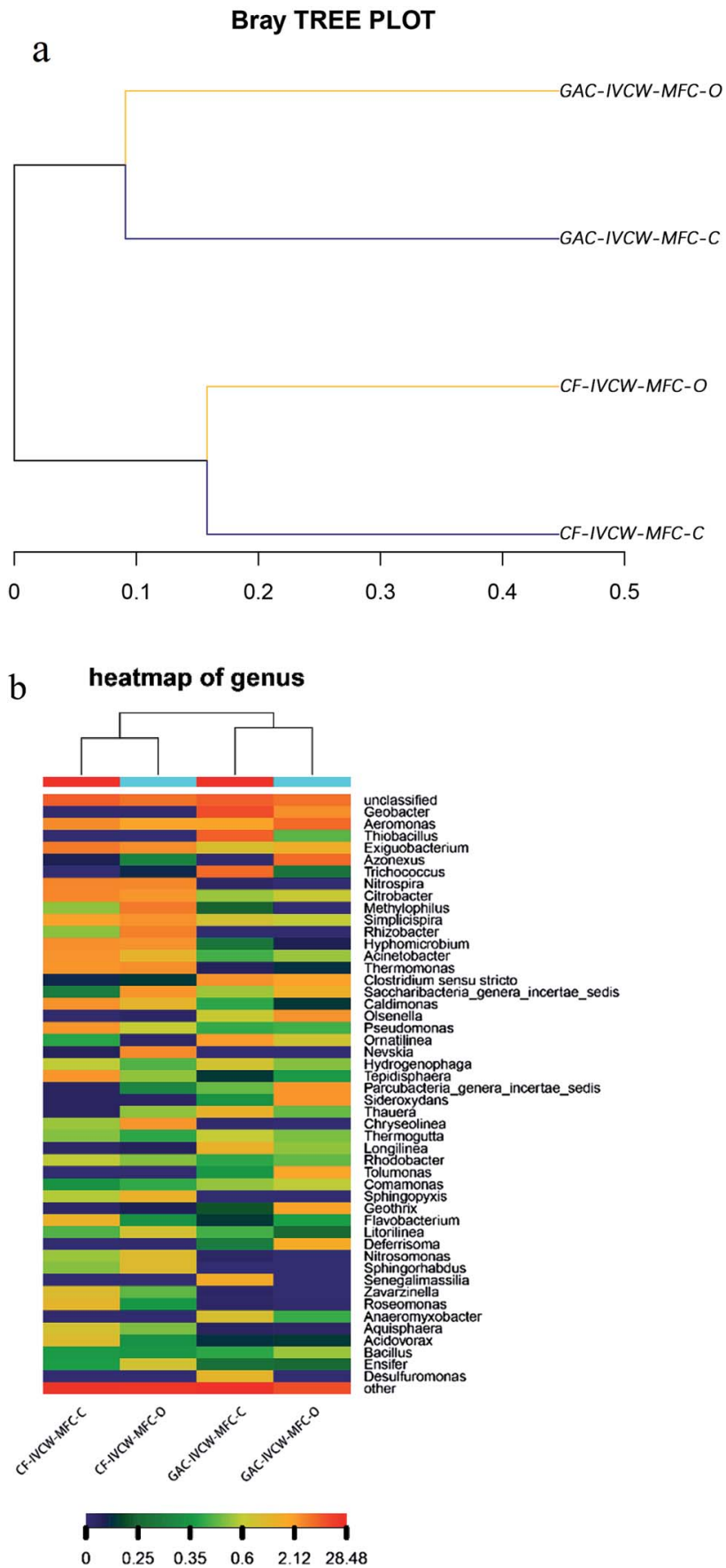

Fig. 5 (a) Bray TREE Plot and (b) a heatmap of each genus. From left to right: CF-IVCW-C, CF-IVCW-O, GAC-IVCW-C, and GAC-IVCW-O. CF is short for carbon felt as the cathode, GAC is short for granularactivated carbon as the anode.

dendrogram cluster analysis showed dissimilarity in the bacterial community structure between the two modes (Fig. 5(a)). Two clear clusters were observed: samples collected together in the anode and cathode regions. This suggested a clear distinction in the microbial community structure between the anode and cathode regions. At the genus-level, Geobacter (with a relative abundance of $17.87 \%$ in the IVCWMFC-C and $3.89 \%$ in the IVCW-MFC-O) was the typical 
anaerobic bacteria, which were detected only in the anaerobic region, but not in aerobic regions. This could be due to the unique structure of the reactor, which forms clear partitions in the anaerobic (anode) and aerobic (cathode) regions.

Fig. 5(b) shows the relative bacterial community abundance characterized at the genus levels to compare the phylogenetic differences in the compositions of the bacterial community structures of the IVCW-MFC-O and IVCW-MFC-C modes. Many researchers have extrapolated that different substrate types could form different exoelectrogenic bacteria community structures. ${ }^{39,40}$ The well-known electrogenic genera, Geobacter and Desulfuromonas, were detected by a genus-level analysis (Fig. 5(b)). Desulfuromonas (Proteobacteria), with a relative abundance of $1.59 \%$, was only detected in the anode surface biofilm under the closed-circuit mode and was not detected in the other three samples. This may due to the IVCW-MFC structure, which provided an extra electron acceptor in the form of the anode to enhance the growth of anaerobia. Geobacter (Proteobacteria), a genus of Fe(III)-oxide reducing bacteria that possesses autohydrogenotrophic denitrification capabilities, was found in anode regions under both open- and closedcircuit modes. It was obvious that the abundance of Geobacter in the IVCW-MFC-C mode was higher than in the IVCW-MFC-O mode. Reguera et $a .^{41}$ and Ganesh et al. ${ }^{42}$ found that Geobacter could be demonstrated to generate currents by pathways involving direct electron transfer and pili. Many electrogenic bacteria, including Geobacter, can directly produce current from acetate without cooperation from other bacteria. ${ }^{39}$ Other bacteria with significant differences in frequency between samples were also identified. Trichococcus (Firmicutes) and Thiobacillus (Proteobacteria) (with relative abundances of $11.59 \%$ and $13.51 \%$, respectively) were more abundant in the anode of the IVCW-MFC-C mode than in the same region of the IVCW-MFC-O mode, and neither could really be found in cathode regions under both open- and closed-circuit modes. Nitrospira (Nitrospirae) and Hyphomicrobium (Proteobacteria) showed the opposite presentation, being more abundant in the cathode of the IVCW-MFC-C mode than in the same region of the IVCW-MFC-O mode and infrequently being found in anode regions under both open- and closed-circuit modes. Notably, Geobacter, Desulfuromonas, Thiobacillus, Hyphomicrobium belong to Proteobacteria, and Trichococcus belongs to Firmicutes. The two phyla Proteobacteria (43.01-57.66\%), and Firmicutes (8.86-25.02\%) were frequently observed in MFCs and could also be recognized in IVCW-MFC-C samples. These two phyla accounted for the majority of the bacterial community, with more than $66.5 \%$ in every sample. Trichococcus (Firmicutes) played an important role in consuming sugar compounds under higher current-producing conditions. ${ }^{40}$ Thiobacillus (Proteobacteria) are Gram-negative betaproteobacteria and denitrifying bacteria using nitrate as electron acceptors, which may bring negative effects to the electrogenesis process in MFCs. Nitrospira (Nitrospirae) and Hyphomicrobium (Proteobacteria) are denitrifying bacteria and could be found in the aerobic/cathode regions. This indicates that various microbes could participate in organic oxidation and/or electricity generation.

\section{Conclusions}

By taking advantage of the structure and substrate distribution of the reactor and combining downflow and upflow effects, the combination of IVCW and MFC proved effective in simultaneously treating swine wastewater and generating bioelectricity. In the IVCW-MFC, the average removal rates of $\mathrm{COD}, \mathrm{NO}_{3}{ }^{-}-\mathrm{N}$, and $\mathrm{NH}_{4}{ }^{+}-\mathrm{N}$ were $79.65 \%, 75.13 \%$, and $77.5 \%$, respectively. The stable output voltage was in the range of $598-713 \mathrm{mV}$, the maximum power density was $0.456 \mathrm{~W} \mathrm{~m}^{-3}$, and the maximum CE was $0.386 \%$. Well-known electrogenic bacteria were detected in the anode surface biofilm under IVCW-MFC-C.

\section{Conflicts of interest}

There are no conflicts to declare.

\section{Acknowledgements}

The authors would like to acknowledge the financial support from the Science and Technology Project of the Education Department of Jiangxi Province of China, No. 170688.

\section{References}

1 L. Doherty, Y. Zhao, X. Zhao and W. Wang, Chem. Eng. J., 2015, 266, 74-81.

2 The First National Census Bulletin of Pollution Sources, Environmental Protection Department of PRC, State Statistical Bureau of PRC, Ministry of Agriculture of PRC, 2010.

3 J. Guo, C. Yang and G. Zeng, Bioresour. Technol., 2013, 143, 289-297.

4 W. Ding, S. Cheng, L. Yu and H. Huang, Chemosphere, 2017, 182, 567-573.

5 P. Klomjek, Sustain. Environ. Res., 2016, 26, 217-223.

6 N. Aryal, T. Kvist, F. Ammam, D. Pant and L. D. M. Ottosen, Bioresour. Technol., 2018, 264, 359-369.

7 S. B. Pasupuleti, S. Srikanth, X. D. Benetton, S. V. Mohan and D. Pant, J. of Chem. Technol. \& Biotech., 2016, 91(3), 624-639.

8 D. Pant, G. V. Bogaert, Y. A. Gallego, L. Diels and K. Vanbroekhoven, Environ. Eng. Manage. J., 2018, 15(8), 1897-1904.

9 H. B. Shen, X. Y. Yong, Y. L. Chen, et al., Bioresour. Technol., 2014, 167, 490-494.

10 C. Corbella, M. Guivernau, M. Viñas and J. Puigagut, Water Res., 2015, 84, 232-242.

11 J. Heilmann and B. E. Logan, Water Environ. Res., 2006, 78(5), 531-537.

12 U. Stottmeister, A. Wiener, K. P. Kusch, et al., Biotechn. Adv., 2003, 22(1), 93-117.

13 Z. Fang, H. L. Song, N. Cang and X. N. Li, Biosens. \& Bioelectron., 2015, 68, 135-141.

14 Z. Fang, S. Cheng, H. Wang, X. Cao and X. Li, RSC Adv., 2017, 7, 16542-16552.

15 S. Freguia, K. Rabaey, Z. Yuan and J. Keller, Water Res., 2008, 42(6), 1387-1396. 
16 Y. L. Oon, S. A. Ong, L. N. Ho, et al., Bioresour. Technol., 2016, 203, 190-197.

17 J. Wei, P. Liang, X. Cao and X. Huang, Bioresour. Technol., 2011, 102, 10431-10435.

18 L. Doherty, Y. Zhao, X. Zhao and W. Wang, Chem. Eng. J., 2015, 266, 74-81.

19 S. Puig, M. Coma, J. Desloover, N. Boon, J. Colprim and M. D. Balaguer, Environ. Sci. Technol., 2012, 46(4), 23092315.

20 P. Srivastava, A. K. Yadav and B. K. Mishra, Bioresour. Technol., 2015, 195, 223-230.

21 J. Sun, Y. Y. Hu, Z. Bi and Y. Q. Cao, Bioresour. Technol., 2009, 100(13), 3185-3192.

22 Z. Ren, T. E. Ward and J. M. Regan, Environ. Sci. Technol., 2007, 41(13), 4781-4786.

23 F. Rezaei, T. L. Richard and B. E. Logan, Biotechnol. Bioeng., 2008, 101(6), 1163-1169.

24 S. Pratiksha, K. Y. Asheesh and K. M. Barada, Bioresour. Technol., 2015, 195, 223-230.

25 R. L. Knight, R. A. Clarke Jr and R. K. Bastian, Water sci. and technol., 2001, 44(11), 27-37.

26 C. T. Onur and Y. Anıl, Ecol. Eng., 2017, 102, 411-421.

27 J. Wang, X. Song, Y. Wang, J. Bai, H. Bai, D. Yan, Y. Cao, Y. Li, Z. Yu and G. Ding, Bioresour. Technol., 2017, 245, 372-378.

28 S. Gajaraj and Z. Hu, Chemosphere, 2014, 117, 151-157.

29 N. H. Thi, C. S. Shing, H. T. Hsu, C. W. Li, N. N. Cong and S. Y. Wu, Ind. Eng. Chem. Res., 2015, 54, 6067-6074.
30 S. Sevdaa, T. R. Sreekishnanb, N. Pousc, S. Puigc and D. Pantd, Bioresour. Technol., 2018, 255, 331-339.

31 J. V. Camacho, M. del C. M. Vico, M. Andrés, R. Rodrigo, F. J. F. Morales and P. C. Cañizares, Environ. Eng. Manage. J., 2014, 10, 2517-2523.

32 Z. Fang, H. Song, N. Cang and X. Li, Bioresour. Technol., 2013, 144, 165-171.

33 O. Lefebvre, Y. Shen, Z. Tan and A. Uzabiaga, Bioresour. Technol., 2011, 102, 5841-5848.

34 Y. Fan, E. Sharbrough and H. Liu, Environ. Sci. Technol., 2008, 42, 8101-8107.

35 L. Doherty, X. Zhao, Y. Zhao and W. Wang, Ecol. Eng., 2015, 79, 8-14.

36 G. Velvizhi and S. V. Mohan, Int. J. Hydrogen Energy, 2012, 37, 5969-5978.

37 Z. A. Stoll, Z. Ma, C. B. Trivedi, J. R. Spear and P. Xu, Chemosphere, 2016, 161, 10-18.

38 J. R. Kim, B. Min and B. E. Logan, Appl. Microbiol. Biotechnol., 2005, 68, 23-30.

39 N. J. Eyiuche, S. Asakawa, T. Yamashita, A. Ikeguchi, Y. Kitamura, H. Yokoyama, et al., BMC Microbiol., 2017, 17(1), 145.

40 X. Mei, C. Guo, B. Liu, Y. Tang and D. Xing, RSC Adv., 2015, 5, $78136-78141$.

41 G. Reguera, K. D. McCarthy, T. Mehta, et al., Nature, 2005, 435, 1098-1101.

42 G. D. Saratale, R. G. Saratale, M. K. Shahid, G. Zhen, et al., Chemosphere, 2017, 178, 534-547. 